\title{
Analysis of an application possibility of geopolymer materials as thermal backfill for underground power cable system
}

\author{
Paweł Ocłoń $^{1}$ (D) Piotr Cisek ${ }^{1} \cdot$ Marcelina Matysiak $^{1}$
}

Received: 5 February 2020 / Accepted: 4 September 2020 / Published online: 20 September 2020

(c) The Author(s) 2020

\begin{abstract}
The circular economy is a closed cycle that allows one to reuse the industrial waste, as well as minimize the energy and resources losses during the production process. This paper presents an innovative idea of the application of a geopolymer cable backfill for underground power cable system installation. The closed cycle, in this case, is formulated as follows: the primary resource is the waste from the combustion of fossil fuels, i.e., fly ash that is utilized to form the geopolymer matrix. The geopolymer then is used as thermal backfill in underground power cable systems. Utilization of combustion by-products in the form of a geopolymer is a highly profitable solution since landfill waste disposal, in this case, generates considerable costs for the electrical energy producers. In typical applications, geopolymers are used as insulators. By adding individual components, the thermal conductivity of $2.0 \mathrm{~W} /(\mathrm{m} \mathrm{K})$, higher than of typical thermal backfills (Fluidized Thermal Backfill), which value is close to $1.5 \mathrm{~W} /(\mathrm{m} \mathrm{K})$, is reached. What is very important, geopolymers can absorb water better than typical sand-cement mixtures. As a result, a high thermal conductivity with the temperature increase is maintained. The application of geopolymers as thermal backfills has the potential to improve the flexibility of underground power cable systems, as well as to minimize the material costs of installation. The case study is presented to show the economic benefits of using the combustion by-products as a geopolymer thermal backfill. The finite element method model of an underground power cable system is developed, and optimization of backfill dimensions is provided to minimize the material costs using the geopolymer thermal backfill and to maximize the underground power cable system performance. The main result of this paper is that the application of geopolymers leads to a decrease in underground power cable system costs, compared to traditional backfill (sand-cement mixture). The reason is the higher value of thermal conductivity, which allows selecting a cable with a smaller cross-sectional area. Also, the environmental benefits of geopolymer application for cable bedding are discussed.
\end{abstract}

\section{Graphic abstract}

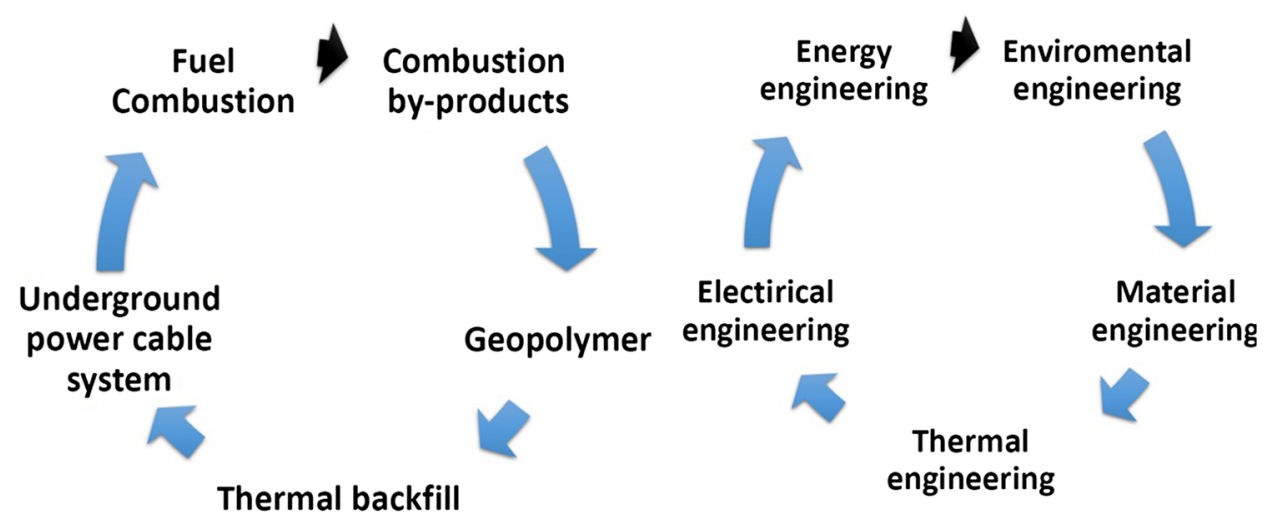

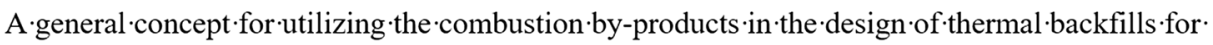
underground power'cable'systems.

Extended author information available on the last page of the article 
Keywords Combustion by-products $\cdot$ Finite element modeling $\cdot$ Geopolymers $\cdot$ Cable backfill

\section{Introduction}

For high voltage (HV) and extra high voltage (EHV) underground transmission lines, the main challenge, apart from the relatively high installation costs, is its limitation in energy transmission. The overall performance depends mainly on the thermal properties of the ground in which it is situated. The burial technique for the power cable installation, as well as the HV power cable cross section, is shown in Fig. 1.

The ampacity of the electricity transmission line is the maximum electrical current safely transferred through the cable conductor without exceeding its maximum operating temperature.

The decrease in the cable conductor area reduces the allowable current transmitted (Shabani and Vahidi 2019). For a high cross-sectional area, larger currents are transferred. The heat generated increases the operating temperature of the cable itself, especially in summer, which can result in cable temperature exceeding $90{ }^{\circ} \mathrm{C}$. This limit value is, in fact, the melting temperature of the XLPE cable insulation. A prolonged increase in the cable operating temperature leads to the melting of the polyethylene insulation and the transmission line failure. The repair time for HV underground transmission lines is about ten times longer than for overhead lines. During the cable line outage time, each hour of electricity supply disruption entails substantial financial losses to the electricity provider. From the reasons mentioned above, the failure rate of $\mathrm{HV}$ and $\mathrm{EHV}$ underground transmission lines must be reduced to a minimum (Nemati et al. 2019).

The arrangement of the Underground Power Cable System (UPCS) in the ground is associated with a considerable and unpredictable variability of environmental parameters, determined by the thermal conductivity of the surrounding soil. When designing HV and EHV UPCS, it is practically abandoned to lay the cable lines directly in the ground. To enhance heat dissipation from the cable core, ensuring moisture retention in a region close to the cable line, a specially designed thermal backfill is used. The thermal backfill needs to provide stable thermal conditions for the cable line operation regardless of the type of surrounding soil. Thermal backfill application during UPCS design and installation brings extensive benefits to the energy system. First of all, cable systems ampacity is raised around $10-15 \%$ by ensuring favorable heat transfer conditions. Also, the cable conductor cross-sectional area is reduced during the design process since expected ampacity will be reached when using a smaller cable. In both cases, significant reductions in construction and operating costs can be achieved.

In Europe, a mixture of sand and Portland cement, in a 12:1 ratio, has been used for years as thermal backfill. Despite its advantages, i.e., low unit price, availability on the market, and adequate mechanical properties, it does not ensure the thermal stability of the cable line operation in the long-term period. After a few months of the thermal load caused by the line operation, its thermal conductivity drops significantly (Ahmad et al. 2019). What is more, the manufacturing of Portland cement caused a considerable (a)

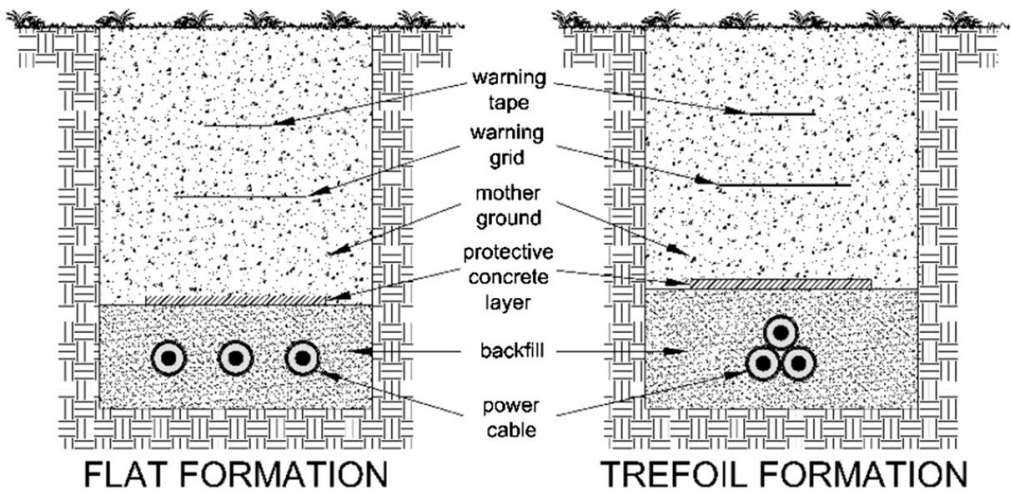

(b)

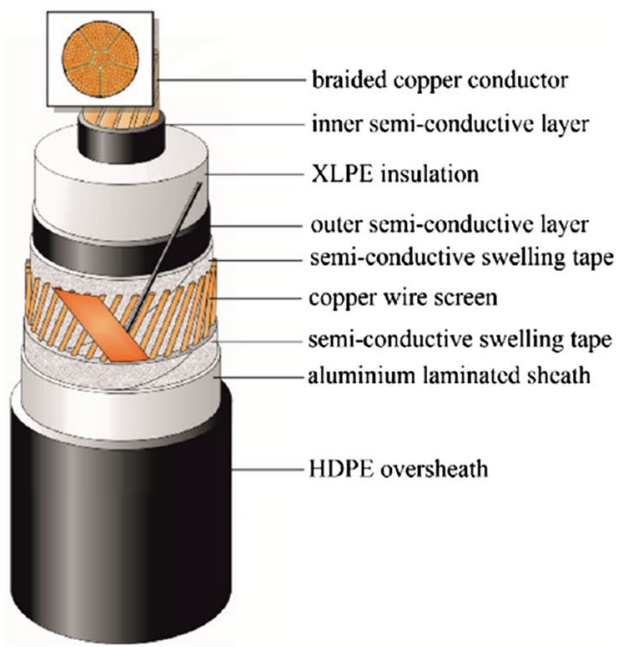

Fig. 1 Cable line burial techniques a direct burial; b $400 \mathrm{kV}$ power cable cross section, according to (Nexans 2011) 
environmental burden and energy efficiency issues (Habert 2013).

The Portland cement is produced at a temperature of $1400-1500{ }^{\circ} \mathrm{C}$ (Huntzinger and Eatmon 2009). During its production, large amounts of $\mathrm{CO}_{2}$ and $\mathrm{NO}_{x}$ are emitted into the atmosphere, as reported by ( $\mathrm{Li}$ et al. 2016). One of the main factors stimulating the development of inorganic polymer technology is the possibility of a real alternative to Portland cement. It is estimated that the synthesis of Portland cement is twice as energy-intensive as the production of geopolymers and causes 4 to 8 times more carbon dioxide emission (Provis and van Deventer 2009). According to several authors (Bajpai et al. 2020; Zhao et al. 2020), using geopolymers as a substitute for Portland cement reduces the environmental load significantly.

In general, geopolymer is a product of alkali activation of any aluminosilicate materials. It consists of long chainscopolymers of silicon and aluminum oxides (fly ash components), as well as stabilizing metal cations, usually sodium, potassium, lithium, or calcium. The alkali activation is performed by mixing $\mathrm{NaOH}, \mathrm{KOH}, \mathrm{Na}_{2} \mathrm{SiO}_{3}$, or $\mathrm{K}_{2} \mathrm{SiO}_{3}$ with fly ash. The geopolymerization occurs at low temperature, usually under $100^{\circ} \mathrm{C}$ and requires no special preparation of the raw material (fly ash) before the process (Zhuang et al. 2016).

The use of geopolymers is a viable alternative to the waste disposal from the energy, mining, and metallurgical sectors. It is possible to reuse considerable amounts of industrial by-products through geopolymerization, therefore minimizing the environmental impact of such waste (Bajpai et al. 2020). That is because geopolymerization is an effective and economically justified method of immobilization of heavy metals, such as $\mathrm{Pb}, \mathrm{Cd}, \mathrm{Cr}$, and $\mathrm{Zn}$, contained in postprocessing waste, in the form of fly ash matrix ( $\mathrm{ach}$ et al. 2018). Also, fly ash is considered a hazardous material since the concentrations of the toxic trace elements in fly ash could be 4-10 times higher than in coal (Boca Santa et al. 2016). Therefore, geopolymerization may be used for stabilizing and solidifying those hazardous substances that would be otherwise disposed into landfills and pollute the environment (Mohajerani et al. 2019). What may confirm the immobilizing nature of geopolymers and its environmental benefits, it is a fact that geopolymerization may be successfully used as well in disposing of medical waste ash (Tzanakos et al. 2014). The authors were able to reduce the leachate of heavy metals concentrations below the permitted limits significantly.

This paper presents the utilization possibility of fluidized bed fly ash and blast furnace slag as raw material for a geopolymer thermal backfill composition. Fluidized bed combustion (FBC) technology is gaining its popularity nowadays since it is a very attractive, efficient, and environmentally friendly coal-combustion technology. FBC enables the utilization of low-grade solid fuels, as hard coal, lignite, municipal, and industrial waste, or biomass when emitting less $\mathrm{NO}_{\mathrm{x}}$ and $\mathrm{SO}_{2}$ compared to traditional coal-combustion technology (Ohenoja et al. 2020). The chemical composition and characteristics of coal ash generated from FBC boilers significantly differ from those of pulverized boilers, as the coal is fired at a relatively lower temperature, and a large amount of limestone is used for desulfurization. Because of a high variation in the produced fly ash quality caused by changes in the fuel composition, FBC fly ash may not be treated as a substitute to the pulverized boiler fly ash. Therefore, FBC fly ash is not used for a Portland cement composition (Zhang et al. 2012). As having low popularity as raw material, fluidized bed fly ash and blast furnace slag are mainly disposed.

The main objective of this paper is to prove that the application of a geopolymer as thermal backfill instead of traditional used sand-cement backfills for cable systems is economically feasible. This study presents an economic analysis of a possible implementation of geopolymer materials for the thermal backfill of UPCS. This idea is presented for the first time. The major part of a geopolymer is a matrix that can be composed of the combustion by-products. The combustion by-product that is assumed to be utilized by using the geopolymer is fluidized bed fly-ash. Therefore, there is no need to pay the costs of those by-products utilization. The analysis is performed for three different prices of $1 \mathrm{~m}^{3}$ of thermal backfill, to show the potential benefits of using geopolymers in this kind of application. In the study, the finite element method (FEM) model of UPCS is used, described in detail in the previous paper (Ocłon et al. 2016). In the article (Ocłoń et al. 2015a), the application FEM for modeling of cable systems situated in a multilayered soil is presented. The optimization procedure, based on PSO (Ocłoń et al. 2015b) and Jaya (Ocłoń et al. 2018) algorithms, is also used to determine the cable backfill area and optimize the UPCS system costs.

\section{A circular economy concept in the design of thermal backfills of underground power cable systems}

Figure 2 shows the concept of utilizing combustion by-products in producing the thermal backfills for the HV and EHV transmission line design and installation.

Fuel combustion produces combustion by-products such as fluidized bed fly ash and blast furnace slag (Hirschi and Chugh 2019). Those materials can be used to form a geopolymer matrix. The use of fly-ash or slag for the production of geopolymers is a pro-ecological approach, as it allows for practical utilization of industrial and energy sector by-products, as fluidized bed fly ash and blast furnace slag. The mass 
Fig. 2 A general concept for utilizing the combustion by-products in the design of thermal backfills for UPCS
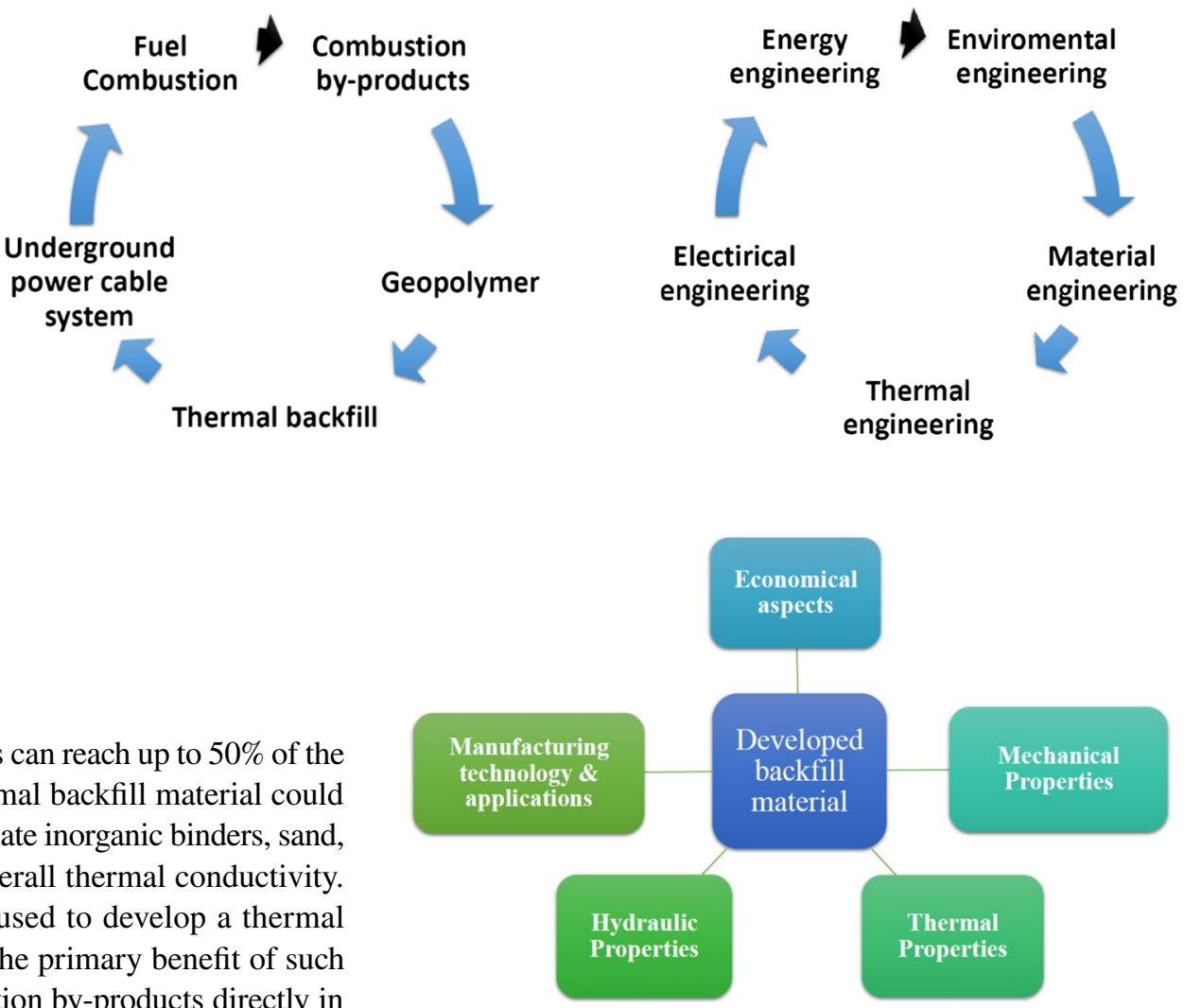

Fig. 3 A set of multidisciplinary aspects that should be considered during the backfill design

\section{UPCS physical model}

Cable manufacturers provide values of power cable ampacity when assuming specific environmental conditions. It gives the possibility to compare similar cable performance and to select a particular model of cable for a given investment case-study. It is a common practice to determine the current ratings based on IEC 60287 using the CYMCAP software (CYME 2020). The current ratings are for the following UPCS working conditions:

- cable line burial depth equal to $2.0 \mathrm{~m}$;

- thermal conductivity of the surrounding soil is equal to $1.0 \mathrm{~W} /(\mathrm{m} \mathrm{K})$;

- ambient air temperature is equal to $30^{\circ} \mathrm{C}$.

The value of soil thermal conductivity is critical for the cable core temperature and the cable ampacity. When assuming a constant value of the soil thermal conductivity, at the level of $1.0 \mathrm{~W} /(\mathrm{m} \mathrm{K})$, according to the IEC 60287,2014 , standard, the cable line designers are forced to use a high safety margin for the calculation results. As a result, a broader cross section of the cable conductor is
Figure 3 shows the various aspects that should be considered when designing the thermal backfills for the UPCS. 
selected than obtained from calculations. The purpose is to ensure reliable operation of the transmission line even when the thermal conductivity of the ground drops below the assumed value. As a result, a significant increase in investment costs of the underground cable line construction is expected to avoid cable overheating.

This study presents an economic analysis of the geopolymer application in the underground transmission line design. The UPCS model is based on the test case considered in practice by the cable line designers. The following assumptions are made:

(1) Constant thermal conductivity of soil equal to $k_{s}=1.0 \mathrm{~W} /(\mathrm{m} \mathrm{K})$

(2) Constant thermal conductivity of thermal backfill $k_{b}$ equal to:

(a) $k_{b}=0.8 \mathrm{~W} /(\mathrm{m} \mathrm{K})$ for the $\mathrm{SCM}$,

(b) $k_{b}=1.4 \mathrm{~W} /(\mathrm{m} \mathrm{K})$ for the geopolymer backfill,

(3) Maximum current load equal to $I=1,200 \mathrm{~A}$

(4) Cable burial depth is $H=2.0 \mathrm{~m}$

It is assumed that the backfill layer dimensions are: $l=0.4 \mathrm{~m}, s, p$, and $b=0.2 \mathrm{~m}$, as it is shown in Fig. 4 .

\section{Heat transfer model in UPCS}

The heat conduction in the UPCS is considered as a twodimensional problem (Eq. (1)). Based on Eq. (1), the highest temperature in the system $T_{\max }$ is calculated. For the present calculation, the $400 \mathrm{kV}$ power cable is composed of a conductor, insulation, and an outer layer. The heat source term is only used for cable core and insulation domains. The adopted model is described in detail in the author's previous work (Ocłoń et al. 2018) and is used for the analysis of geopolymer-based thermal backfill materials of power cables.

$\left\{\begin{array}{l}k_{c} \frac{\partial^{2} T}{\partial x^{2}}+k_{c} \frac{\partial^{2} T}{\partial y^{2}}=-q_{v, c}, \text { cable core domain } \\ k_{\text {ins }} \frac{\partial^{2} T}{\partial x^{2}}+k_{i n s} \frac{\partial^{2} T}{\partial y^{2}}=-q_{\text {ins }}, \text { cable insulation domain } \\ k_{\text {ext }} \frac{\partial^{2} T}{\partial x^{2}}+k_{e x t} \frac{\partial^{2} T}{\partial y^{2}}=0, \text { cable outer layer domain } \\ k_{s} \frac{\partial^{2} T}{\partial x^{2}}+k_{s} \frac{\partial^{2} T}{\partial y^{2}}=0, \text { ground domain } \\ k_{b} \frac{\partial^{2} T}{\partial x^{2}}+k_{b} \frac{\partial^{2} T}{\partial y^{2}}=0, \text { cable backfill domain }\end{array}\right.$

where,

$x, y: x$ and $y$ coordinates at a specific location, $q_{v}$ : heat flux, $\mathrm{W} / \mathrm{m}^{2}$.

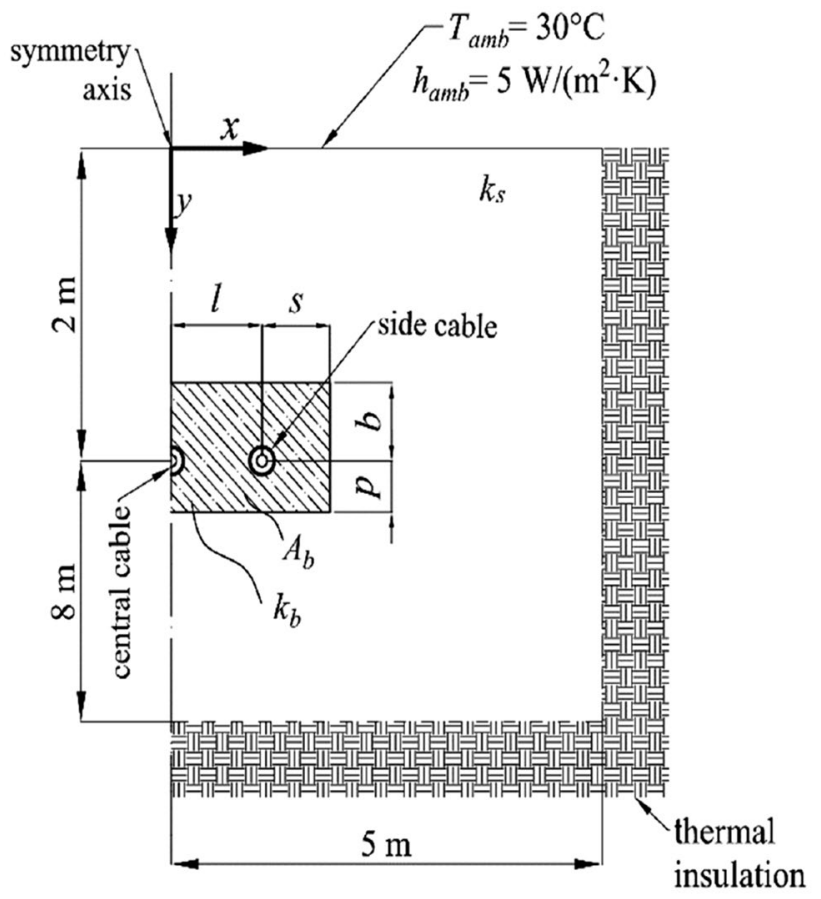

$k_{s}=1.0 \mathrm{~W} /(\mathrm{m} \cdot \mathrm{K})$ for a mother ground $k_{b}=1.4 \mathrm{~W} /(\mathrm{m} \cdot \mathrm{K})$ for a geopolymer backfill $k_{b}=0.8 \mathrm{~W} /(\mathrm{m} \cdot \mathrm{K})$ for a sand-cement mix

Fig. 4 Scheme of the UPCS being considered during the computations

$k$ : thermal conductivity of specific layers:

- $k_{c}=400 \mathrm{~W} /(\mathrm{m} \mathrm{K})$ - the domain of cable core,

- $k_{\text {ins }}=0.285 \mathrm{~W} /(\mathrm{m} \mathrm{K})$ - the domain of insulation,

- $k_{\text {ext }}=0.57 \mathrm{~W} /(\mathrm{m} \mathrm{K})$ - the domain of cable external layer,

- $k_{s}=1.0 \mathrm{~W} /(\mathrm{m} \mathrm{K})$ - the domain of ground,

- $k_{b}=0.8 \mathrm{~W} /(\mathrm{m} \mathrm{K})$ - the domain of sand-cement mix (SCM),

- $k_{b}=1.4 \mathrm{~W} /(\mathrm{m} \mathrm{K})$ - the domain of geopolymer

The system of governing differential equations, given in Eq. (1), is subjected to boundary conditions, shown in Fig. 4. The ambient temperature $T_{a m b}$ is considered to be equal to $30{ }^{\circ} \mathrm{C}$ (conditions in the summertime when the air temperature is high). The air heat transfer coefficient $h_{a m b}$ is assumed as $5.0 \mathrm{~W} /\left(\mathrm{m}^{2} \mathrm{~K}\right)$. The right and bottom sides of the heat transfer domain are insulated, while the symmetry boundary condition is applied at the symmetry plane of the UPCS domain. The last assumption allows one to reduce the number of finite elements and decrease the computational time. 
$\left.k_{s} \frac{\partial T}{\partial x}\right|_{x=5 m}=0$

$\left.k_{s} \frac{\partial T}{\partial x}\right|_{x=0}=0$

$\left.k_{s} \frac{\partial T}{\partial y}\right|_{y=10 m}=0$

$\left.k_{s} \frac{\partial T}{\partial y}\right|_{y=0}=h_{a m b}\left(T-T_{a m b}\right)$

After discretization, the resulting nonlinear system of differential equations is solved, and the nodal temperatures are determined. The procedures described in IEC 60287, 2014, standard are used to calculate the cable core and insulation heat losses.

\section{Determination of cable core and insulation heat loss}

Equation (3) provides the formula for heat losses in cable core (Anders 1997; Thue 2011):

$q_{v, c}(T(x, y))=\frac{\Delta Q_{c}}{A_{c, c a l}}$

where

$\Delta Q_{c}=\frac{I^{2} \rho_{20} C}{A_{c, c a l}}\left[1+\alpha_{r e f}\left(T_{c}(x, y)-T_{r e f}\right)\right]\left(1+y_{s}+y_{p}\right)$

and.

$\rho_{20}=1.7241 \times 10^{-8} \Lambda \mathrm{m}-$ copper electrical resistance,

$C=1.02 \mathrm{~m}-$ sample length,

$T_{\text {ref }}=20^{\circ} \mathrm{C}$-reference temperature,

$T_{c}$ - the average cable conductor temperature ${ }^{\circ} \mathrm{C}$,

$\alpha_{\text {ref }}=0.00393$ - copper conductor temperature coefficient,

$\Delta Q_{c}$ - cable conductor heat loss, W/m,

$d_{c}$-power cable core equivalent diameter for $400 \mathrm{kV}$ power cables, $\mathrm{m}$,

$y_{s}$ and $y_{p}-$ skin and proximity effect factors.

XLPE HV power cable equivalent cross-sectional area $A_{c, c a l}$ is given by:

$A_{c, c a l}=\left(\sum_{i=0}^{3} p_{i, c} A_{c}^{i}\right)$

with $p_{0, i}$ to $p_{3, i}$ coefficients equal to $p_{0, i}=0.0007955$, $p_{1, i}=0.3697, p_{2, i}=-6.04, p_{3, i}=1.673 \times 10^{5}$.

The skin and proximity factors, $y_{s}$ and $y_{p}$, are obtained based on IEC 60287, 2014, standard.

When defining $x_{s}$, the following formula is used:

$x_{s}=\frac{8 \pi f}{R^{\prime}} \cdot 10^{-7} K_{s}$,

where
$R^{\prime}=\frac{I^{2} \rho_{20} C}{A_{c, c a l}}\left[1+\alpha_{r e f}\left(T_{c}(x, y)-T_{r e f}\right]\right.$

skin effect factor $y_{s}$ is calculated as follows:

$y_{s}=\frac{x_{s}^{4}}{192+0.8 x_{s}^{4}}, \quad$ for $\quad 0<x_{s} \leq 2.8$,

$y_{s}=-0.136-0.0177 x_{s}+0.0563 x_{s}^{2}, \quad$ for $2.8<x_{s} \leq 3.8$,

and

$y_{s}=0.354 x_{s}-0.733$, for $x_{s}>3.8$.

For a given value of $x_{p}$ :

$x_{p}=\frac{8 \pi f}{R^{\prime}} \cdot 10^{-7} K_{p^{\prime}}$,

the proximity effect factor $y_{p}$ is calculated as:

$y_{p}=\frac{x_{p}^{2}}{192+0.8 x_{p}^{2}}\left(\frac{d_{c}}{l}\right)^{2}\left[0.312\left(\frac{d_{c}}{l}\right)^{2}+\frac{1.18}{\frac{x_{p}^{2}}{192+0.8 x_{p}^{2}+0.27}}\right]$

In Eqs. (6)-(12), $l$ is a distance between cables, and $f$ is an alternating current frequency, equal to $50 \mathrm{~Hz}$. The value of $K_{s}$ and $K_{p}$, is equal to 0.37 and 0.8 , according to ICE 60287, 2014. The Round Milliken bare bi-directional wires are considered.

The value of $q_{v \text {,ins }}$, referred to the insulation cross-sectional area $A_{\text {ins, cal }}$, is determined by:

$q_{v, \text { ins }}=\frac{\Delta Q_{\text {ins }}}{A_{\text {ins,cal }}}$

where

$\Delta Q_{\text {ins }}=2 \pi f C_{i n s} \frac{U^{2}}{3 t} \tan \delta$

when the given parameters are:

$C_{\text {ins }}$-capacitance calculated according to Nexans (2011), F/m,

$\tan \delta$-insulation loss factor equal to $\tan \delta=0.005$,

$U$ - the maximum AC voltage, $\mathrm{V}$.

The value of $A_{\text {ins,cal }}$ is determined as:

$A_{\text {ins }, c a l}=\left(\sum_{i=0}^{3} p_{i, i n s} A_{c}^{i}\right)$

with $p_{0, \text { ins }}$ to $p_{3, \text { ins }}$ coefficients equal to: $p_{0, \text { ins }}=0.002695$, $p_{1, \text { ins }}=4.725, p_{2, \text { ins }}=-1590, p_{3, \text { ins }}=2.72 \times 10^{5}$. 


\section{Calculation of UPCS costs (thermal backfill and cables costs)}

The material costs of the UPCS can be calculated as:

$$
C_{\text {sys }}=C_{\text {cable }}+C_{\text {back }} \cdot A_{b}-w_{c b p} C_{u t} A_{b}
$$

where $C_{\text {cable }}$ is the cost of cables in the UPCS in $\$ / \mathrm{km}, C_{\text {back }}$ is a unit cost of cable backfill material with $1 \mathrm{~m}^{2}$ crosssectional area and $1 \mathrm{~km}$ length, $w_{c b p}$ is a fraction of combustion by-products in geopolymer thermal backfill (assumed as equal to 0.5), and $C_{u t}$ is the cost of the utilization of $1 \mathrm{t}$ of combustion-by-products (assumed to be equal $100 \$ / \mathrm{t}$ ).

\section{Results and discussion}

The calculations were performed using the own FEM code written in MATLAB. Figure 5 shows the temperature fields obtained for sand-cement mix thermal backfill and geopolymer thermal backfill. It is possible to observe that the application of geopolymer thermal backfill reduces the temperature in the region close to cable core, due to the higher thermal conductivity than of the sand-cement mixture.

The economic benefits of the application of a geopolymer are observed for different prices of the $1 \mathrm{~m}^{3}$ of thermal backfill (Fig. 6). The overall costs of the cable system are calculated for the considered price of thermal backfill equal to 100 \$, 150 \$, and 200 \$. The SCM thermal backfill costs are assumed to be equal to $30 \$ /$ $\mathrm{m}^{3}$. Figure $6 \mathrm{c}$ shows the variation of a single power cable cost concerning the cable cross section. Figure 6a shows the scenario when the prices of a geopolymer thermal backfill are equal to $100 \$$. Due to the significant savings of the company on utilizing of the combustion byproducts, the overall costs of the cable system $C_{\text {sys }}$ are only slightly higher for the same cable conductor cross section $A_{c}$, than the costs when the sand-cement mixture is applied. What is essential is a fact that when the geopolymer thermal backfill with thermal conductivity of $k_{b}=1.4 \mathrm{~W} /(\mathrm{m} \mathrm{K})$ is used, then the temperature of the cable core is less than $90{ }^{\circ} \mathrm{C}$, the maximum temperature
Fig. 5 Temperature $\left(\right.$ in $\left.{ }^{\circ} \mathrm{C}\right)$ distribution in the system for sandcement mix and geopolymer sand-cement mix
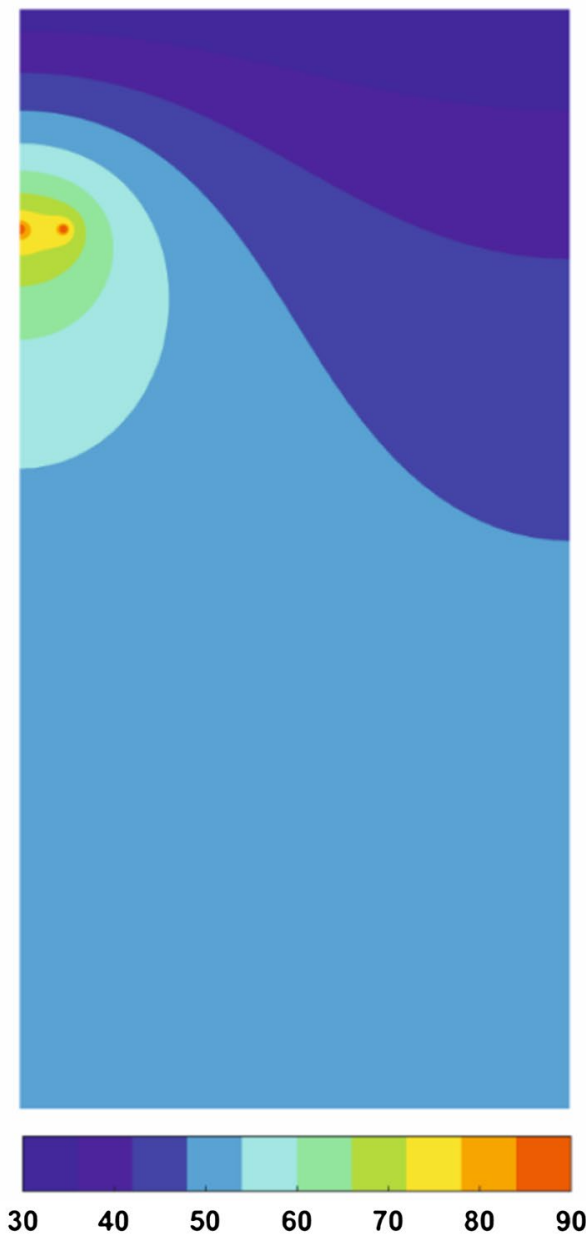

geopolymer
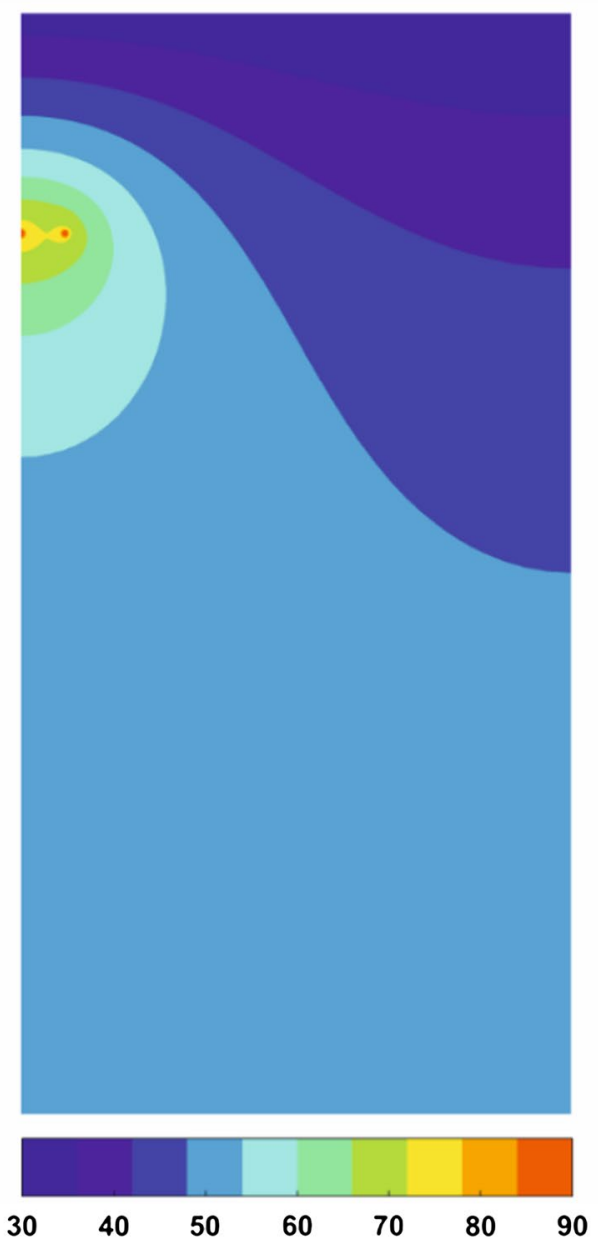


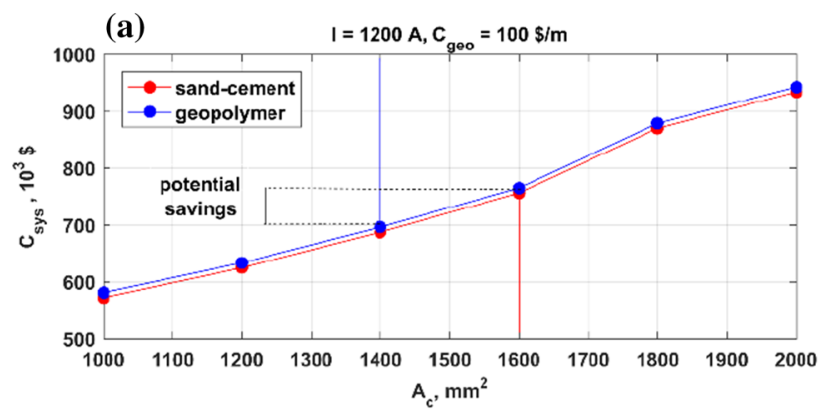

(b)

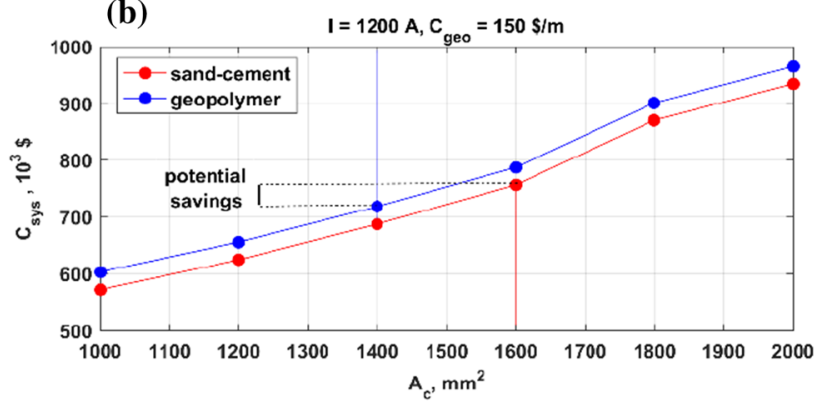

(c)

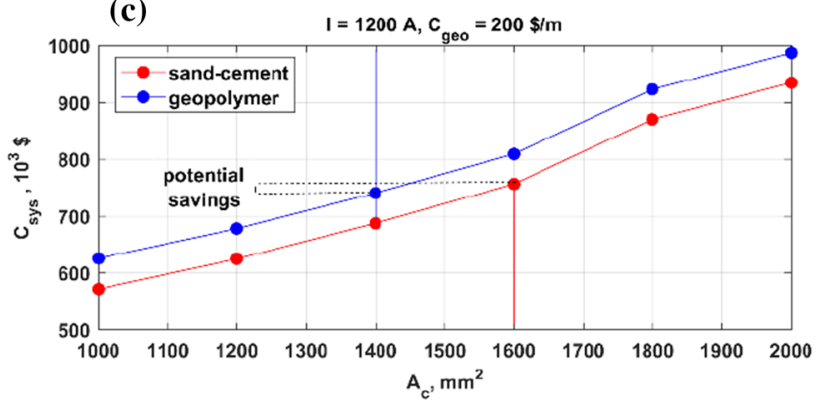

(d)

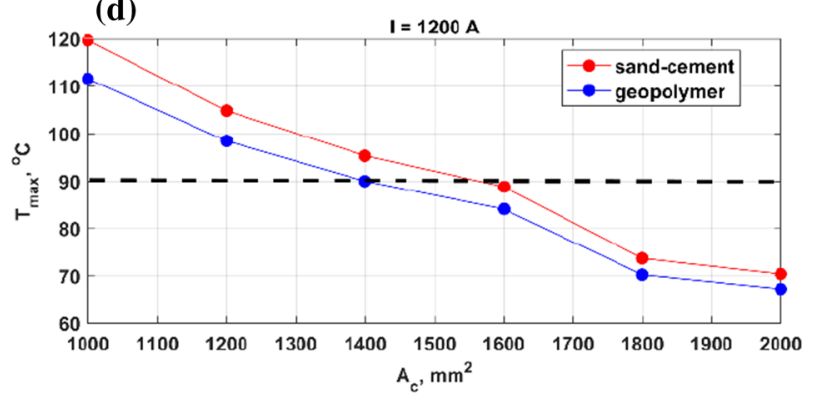

(e)

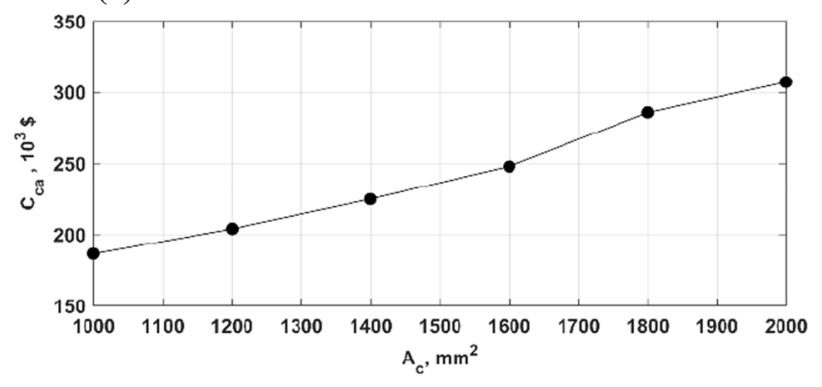

(f)

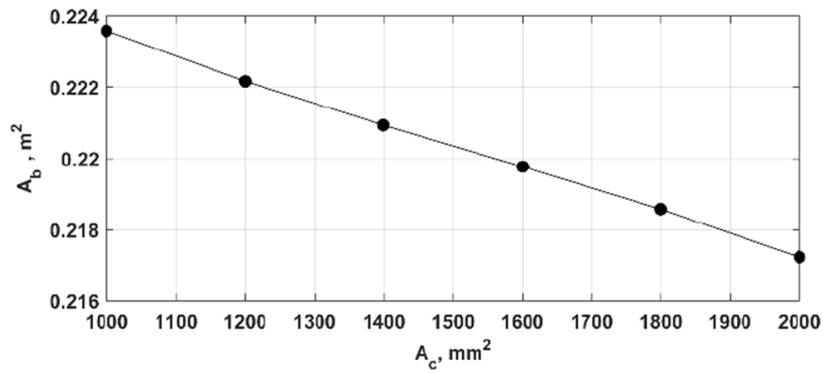

Fig. 6 Material costs of the UPCS installation, when the geopolymer price is set as a $100 \$ / \mathrm{km}$; b $150 \$ / \mathrm{km}$; c $200 \$ / \mathrm{km}$; d cable conductor maximum temperature; e cost of the single power cable in $10^{3} \$ / \mathrm{km}$; $\mathbf{f}$ area of thermal backfill applied

of cable operation, if one applied cables with $A_{c}=1400$ $\mathrm{mm}^{2}$. When the sand-cement mixture is used as thermal backfill, the cable core temperature is significantly higher than $90{ }^{\circ} \mathrm{C}$ (Fig. 6d). The cables with a larger cross-sectional area of $1600 \mathrm{~mm}^{2}$ shall be used. The potential saving arising from the application of a geopolymer thermal backfill can reach over $60,000 \$ / \mathrm{km}$ of cable line for this case study.

In case, when the geopolymer thermal backfill price is set as $150 \$ / \mathrm{m}^{3}$ (Fig. 6b), the potential savings are smaller, but still remunerative with over $30,000 \$ / \mathrm{km}$ of the cable line. In a case when the geopolymer thermal backfill costs are $200 \$ / \mathrm{m}^{3}$ (Fig. 6c), then the potential economic benefits of replacement of the sand-cement mixture with geopolymer are limited to $10,000 \$ / \mathrm{km}$ of the cable line. Based on the performed calculations, it is evident that applying the dedicated backfill materials like geopolymers reduces the overall costs of the UPCS compared to the traditional sand-cement mixture.

\section{Eco-environmental analysis}

Application of the geopolymer thermal backfill for HV and EHV underground transmission line installation can be considered in technical, economical, and environmental aspects.

As presented in Fig. $6,0.448 \mathrm{~m}^{2}$ cross-sectional area of the geopolymer backfill may be applied for the case-study since the $A_{b}$ value is calculated for half of the system considered (Fig. 4). Therefore, around $448 \mathrm{~m}^{3} / \mathrm{km}$ of backfill needs to be applied for each $\mathrm{km}$ of the designed cable line length. On the contrary, in engineering calculations and during the UPSC design, the rectangular shape of SCM backfill with $1.4 \mathrm{~m}$ width and $0.4 \mathrm{~m}$ height is commonly applied. Thus, approximately $522 \mathrm{~m}^{3} / \mathrm{km}$ of the SCM is needed. Consequently, the presented approach and detailed thermal analysis of UPCS operation result in decreasing in backfill use for about $74 \mathrm{~m}^{3} /$ $\mathrm{km}$ (more than 14\%). That significant reduction in backfill area may be reached by replacing SCM $\left(k_{b}=0.8 \mathrm{~W} /(\mathrm{m} \mathrm{K})\right)$, with the geopolymer backfill $\left(k_{b}=1.4 \mathrm{~W} /(\mathrm{m} \mathrm{K})\right)$. When considering 
backfill prices, SCM for the transmission line installation costs $15,660 \$ / \mathrm{km}$ and 44,800 \$/km for the geopolymer backfill.

As mentioned earlier in the text, the mass content of combustion by-products in a geopolymer matrix can reach up to $50 \%$ of the backfill weight. When assuming the dry density of thermal backfill approximately $1.850 \mathrm{t} / \mathrm{m}^{3}$ (Radhakrishna 1982), it gives around $414.4 \mathrm{t} / \mathrm{km}$ of combustion by-products utilized per each $\mathrm{km}$ of $\mathrm{HV}$ and EHV transmission line built. As reported by (American Coal Ash Association 2018), disposal costs of coal by-products depend on multiple factors, as the specific type of combustion waste, location, transportation methods, climate and terrain, regulatory requirements, and potential for its future use. For the most unfavorable conditions, the price may reach 20 to $40 \$ / t$ of coal combustion waste disposed. When a disposal site is located near the power plant and the material being disposed can be easily handled, the price may decrease to $3-5 \$ / t$. When taking into account the costs of the combustion waste disposal around $10 \$ / t$, benefits from its utilization in the form of the geopolymer backfill may give about $4144 \$ / \mathrm{km}$ savings for the transmission line length. On the contrary, Portland cement prices have reached a level of $123.5 \$ / t$, according to (Statista 2020), which gives approximately $9.51 \$ / t$ of the SCM.

The detailed carbon footprint analysis for geopolymer and Portland cement concrete is performed by (Turner and Collins 2013). According to (Turner and Collins 2013), equivalent $\mathrm{CO}_{2}$ emission during the Portland cement manufacturing reaches $820 \mathrm{~kg} \mathrm{CO}_{2}$-e/t. The fly ash and other coal by-products are considered zero or minimal $\mathrm{CO}_{2}$-e contribution. For the fly ash, it is $27 \mathrm{~kg} \mathrm{CO}_{2}$-e/t. What is important, geopolymer backfill composition also requires the alkali activator (sodium hydroxide) as well as sodium silicate, which along with fly ash and $\mathrm{NaOH}$, creates the geopolymer binder. According to (Turner and Collins 2013), the total equivalent $\mathrm{CO} 2$ emission reaches $108.56 \mathrm{~kg} \mathrm{CO} 2$-e/t for a mixture of fly ash, sodium hydroxide, and sodium silicate for the geopolymer concrete composition. As the investigation of the proper geopolymer backfill composition is still in progress, it is impossible to evaluate its environmental footprint properly. After rough estimation environmental costs for the SCM application may reach around $60,974 \mathrm{~kg}$ $\mathrm{CO}_{2}$-e/km, and for the geopolymer backfill should be lower than $90,048 \mathrm{~kg} \mathrm{CO}_{2}-\mathrm{e} / \mathrm{km}$. What should be stressed, the final composition of the geopolymer backfill is not known yet. Therefore, it is impossible to assess its total carbon footprint.

\section{Conclusions}

The HV and EHV underground transmission lines are widely used nowadays. To allow the proper operation of the system, not to exceed the maximum allowable conductor temperature equal to $90{ }^{\circ} \mathrm{C}$ is needed. Thermal backfill materials are used to improve the heat transfer from power cables. The commonly used sand-cement mixture has low thermal conductivity, which in the dry state is equal to $0.8 \mathrm{~W} /(\mathrm{m} \mathrm{K})$. There is a need to develop a novel and not expensive thermal backfill materials with higher thermal conductivity. The option here could be geopolymers with a matrix based on fluidized boilers fly-ash, which is challenging to utilize. This study shows the potential economic benefits of the application of this kind of fuel combustion by-products as thermal backfill. For a flat-formation of the UPCS, with the maximum current of 1,200 A, the computations were carried out. It was assumed that the costs of fluidized bed combustion by-products utilization are of $100 \$ / \mathrm{t}$. A reasonable value of geopolymer thermal conductivity equal to $1.4 \mathrm{~W} /(\mathrm{m} \mathrm{K})$, and three cost levels of $100 \$ / \mathrm{m}^{3}, 150 \$ / \mathrm{m}^{3}$, and $200 \$ / \mathrm{m}^{3}$ of thermal backfill were assumed.

The computations showed that in a case when the costs of geopolymer thermal backfill are of $100 \$ / \mathrm{m}^{3}$ of thermal backfill, the potential saving in cable system design can lead up to $60,000 \$ / \mathrm{km}$ savings of cable system material cost. The reason is the possible use of a cable with a smaller cross-sectional area, i.e., $1400 \mathrm{~mm}^{2}$ (when geopolymer thermal backfill is used), compared to the one applied for sand-cement mix thermal backfill, i.e., $1600 \mathrm{~mm}^{2}$. Therefore, the utilization of fluidized-bed combustion by-products can create potential economic benefits for the energy distribution industry.

Summing up, geopolymers application in backfilling technology for the HV and EHV underground transmission seems to be promising. By using industrial waste and turning it into a full-value product may surely bring many benefits. Nevertheless, extensive and multidisciplinary studies must be performed to investigate the preferable composition of the backfill. Also, the material test should be conducted to check if the backfill does not interfere with the power cable sheath, causing its corrosion, among others.

Open Access This article is licensed under a Creative Commons Attribution 4.0 International License, which permits use, sharing, adaptation, distribution and reproduction in any medium or format, as long as you give appropriate credit to the original author(s) and the source, provide a link to the Creative Commons licence, and indicate if changes were made. The images or other third party material in this article are included in the article's Creative Commons licence, unless indicated otherwise in a credit line to the material. If material is not included in the article's Creative Commons licence and your intended use is not permitted by statutory regulation or exceeds the permitted use, you will need to obtain permission directly from the copyright holder. To view a copy of this licence, visit http://creativecommons.org/licenses/by/4.0/. 


\section{References}

Ahmad S, Rizvi Z, Khan MA, Ahmad J, Wuttke F (2019) Experimental study of thermal performance of the backfill material around underground power cable under steady and cyclic thermal loading. Mater Today Proceed 17(1):85-95

American Coal Ash Association (ACAA) (2018) Frequently asked questions about coal ash, https://www.acaa-usa.org/aboutcoala sh/ccpfaqs.aspx. Accessed 5 April 2020.

Anders GJ (1997) Rating Of electric power cables: ampacity computations for transmission, distribution, and industrial applications. Institute of Electrical \& Electronics Engineers (IEEE) Press, New York.

Bajpai R, Choudhary K, Srivastava A, Sangwan KS, Singh M (2020) Environmental impact assessment of fly ash and silica fume based geopolymer concrete. J Cleaner Prod 254:120147

Boca Santa RAA, Soares C, Riella HG (2016) Geopolymers with a high percentage of bottom ash for solidification/immobilization of different toxic metals. J Hazardous Mater 318:145-153

CYME (2020) CYMCAP_-Power Cable Ampacity Rating (2020) https ://www.cyme.com/software/cymcap/

Habert G (2013) Environmental impact of Portland cement production. In: Pacheco-Torgal F, Jalali S, Labrincha J, John VM (eds) Civil and structural engineering, eco-efficient concrete. Woodhead Publishing, Cambridge, pp 3-25.

Hirschi JC, Chugh YP (2019) Sustainable coal waste disposal practices, chapter. In: Hirschi JC (ed) Advances in productive, safe, and responsible coal mining. Woodhead Publishing, Cambridge, pp 245-269

Huntzinger DN, Eatmon TD (2009) A life-cycle assessment of Portland cement manufacturing: comparing the traditional process with alternative technologies. J Clean Prod 17(7):668-675

IEC 60287-1-1:2006/AMD1:2014 standard (2014) Electric cablesCalculation of current rating-Part 1: Current rating equations (100\% load factor) and calculation of losses-Section 1: General.

Li Y, Liu Y, Gong X, Nie Z, Cui S, Wang Z, Chen W (2016) Environmental impact analysis of blast furnace slag applied to ordinary Portland cement production. J Clean Prod 120(1):221-230

Łach M, Mierzwiński D, Korniejenko K, Mikuła J, Hebda M (2018) Geopolymers as a material suitable for immobilization of fly ash from municipal waste incineration plants. J Air Waste Manage Assoc 68(11):1190-1197

Mohajerani A, Suter D, Jeffrey-Bailey T (2019) Recycling waste materials in geopolymer concrete. Clean Techn Environ Policy 21:493-515

Nemati HM, Anita Sant'Anna, Sławomir Nowaczyk, Jan Henning Jürgensen, Patrik Hilber (2019) Reliability evaluation of power cables considering the restoration characteristic. Int JElectrical Power Energy Syst 105:622-631

Nexans (2011) High voltage underground power cables, 60-500 kV high voltage underground power cables XLPE insulated cables. Available online:https://www.nexans.com/Corporate/2013/60500_kV_High_Voltage_full_BD2.pdf

\section{Affiliations}

\section{Paweł Ocłoń $^{1}$ (D) Piotr Cisek ${ }^{1} \cdot$ Marcelina Matysiak $^{1}$}

\section{Paweł Ocłoń}

pawel.oclon@pk.edu.pl
Ocłoń P, Bittelli M, Cisek P, Kroener E, Pilarczyk M, Taler D, Rao RV, Vallati A (2016) The performance analysis of a new thermal backfill material for underground power cable system. Appl Thermal Eng 108:233-250

Ocłoń P, Cisek P, Pilarczyk M, Taler D (2015a) Numerical simulation of heat dissipation processes in underground power cable system situated in thermal backfill and buried in a multilayered soil. Energ Convers Manage 95:352-370

Ocłoń P, Cisek P, Taler D, Pilarczyk M, Szwarc T (2015b) Optimizing of the underground power cable bedding using momentum-type particle swarm optimization method. Energy 92:230-239

Ocłoń P, Cisek P, Rerak M, Taler D, Rao RV, Vallati A, Pilarczyk M (2018) Thermal performance optimization of the underground power cable system by using a modified Jaya algorithm. Int $\mathrm{J}$ Thermal Sci 123:162-180

Ohenoja K, Pesonen J, Yliniemi J, Illikainen M (2020) Utilization of fly ashes from fluidized bed combustion: a review. Sustainability 12(7):2988

Provis JL, van Deventer JSJ (eds) (2009) Geopolymers: structure, processing, properties and industrial applications. Woodhead Publishing, Cambridge

Radhakrishna HS (1982) Fluidized cable thermal backfill. In: Boggs SA et al (eds) Underground cable thermal backfill. Pergamon Press, Oxford.

Shabani H, Vahidi B (2019) A probabilistic approach for optimal power cable ampacity computation by considering uncertainty of parameters and economic constraints. Int J Electrical Power Energ Syst 106:432-443

Statista (2020) Cement prices in the United States from 2007 to 2019. https://www.statista.com/statistics/219339/us-prices-of-cemen $\mathrm{t} /$ \#statisticContainer.

Thue WA (2011) Electrical power cable engineering, 3rd edn. CRC Press, Boca Raton

Turner LK, Collins FG (2013) Carbon dioxide equivalent $\left(\mathrm{CO}_{2}\right.$-e) emissions: a comparison between geopolymer and OPC cement concrete. Constr Build Mater 43:125-130

Tzanakos K, Mimilidou A, Anastasiadou K, Stratakis A, Gidarakos E (2014) Solidification/stabilization of ash from medical waste incineration into geopolymers. Waste Manag 34(10):1823-1828

Zhang Z, Qian J, You C, Hu C (2012) Use of circulating fluidized bed combustion fly ash and slag in autoclaved brick. Constr Build Mater 35:109-116

Zhao X, Liu C, Zuo L, Wang L, Zhu Q, Liu Y, Zhou B (2020) Synthesis and characterization of fly ash geopolymer paste for goaf backfill: Reuse of soda residue. J Clean Prod 260:121045

Zhuang XY, Chen L, Komarneni S, Zhou CH, Tong DS, Yang HM, Hua W, Wang H (2016) Fly ash-based geopolymer: clean production, properties and applications. J Clean Prod 125:253-267

Publisher's Note Springer Nature remains neutral with regard to jurisdictional claims in published maps and institutional affiliations.
Department of Energy, Faculty of Environmental and Energy Engineering, Cracow University of Technology, Al. Jana Pawła II 37, 31-864, Kraków, Poland 